Conference Proceedings - Short Paper

\title{
Innovative financial mechanisms and stakeholders involvement for climate resilience implementation in Himalayan cities
}

\author{
Ramiz Khan \\ Internacional de Catalunya (UIC), Barcelona, Spain \\ E-Mail: ramiz.rk@gmail.com \\ * Author to whom correspondence should be addressed; Tel.: +34 602092926;
}

${ }^{1}$ Faculty of Architecture, Technical University of Darmstadt, Darmstadt, Germany and Universitat

\begin{abstract}
The Indian Himalayan region is considered as one of the global hotspots for Climate change. The climate change impact poses additional stress on these cities and its residents and exacerbates the existing challenges on such as Water scarcity, drainage and solid waste management. This article represents a case example from three cities in the Indian Himalayan region (Shimla, Kurseong, Gangtok) and their resilience strategy formulation using ICLEI ACCCRN Process (IAP) toolkit and the process of laying the path to move from developing climate resilience strategies to project implementation through an active stakeholder engagement. Shimla and Kurseong brought forth water supply systems as one of the most fragile urban systems. Whereas, Gangtok recognized the essential need to adopt a proper Solid Waste Management system, especially to avoid clogging of open drains and natural streams in order to reduce the threat of landslide incidences that result in infrastructural, financial and human loss. This case study also focuses on innovative financing mechanism by linking the projects with the Small Grants Fund to create success stories which can further be upscale through convergence with existing federal government schemes.
\end{abstract}

Keywords: Resilience, ICLEI ACCCRN Process (IAP), Shared Learning Dialogue (SLD), Stakeholders, Climate Core Committee

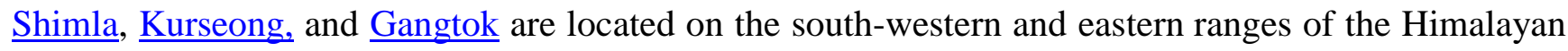
respectively. With support from the Rockefeller Foundation along with ICLEI - Local Government for Sustainability, South Asia they have developed the city resilience strategies using ICLEI ACCCRN Process (IAP), under the Asian Cities Climate Change Resilience Network (ACCCRN). The IAP toolkit 
is centered on active stakeholder engagement called the Shared Learning Dialogue (SLD), which facilitates multi-dimensional information sharing with everyone contributing information and experiences and everyone learning from the exchanges. The city governments (Municipalities as Nodal Agencies) were facilitated by ICLEI South Asia to run the IAP process.

SLDs in Shimla and Kurseong brought forth the water sector, especially water supply systems as one of the most fragile urban systems. Some of the key issues faced by these cities were that water supply infrastructures are very old and not capable of supporting the current population, degradation of the catchment areas, and deforestation leading to increased surface runoff and reduced retention/infiltration. For instance, as per the City Resilience Strategy, the water supply system of Shimla dates back to 1875. The demand for water increases from 42 MLD to 45 MLD during the peak summer season due to additional pressure from the incoming tourists, while the supply ranges between 24 to 27 MLD. Local residents have been forced to spend working hours standing in long queues to fetch water from water tanks provided by the municipality. Tourism is one of the primary sources of income in the Shimla city. However, due to water scarcity, hotels are compelled to turn away guests and refund bookings. In Kurseong too, the situation is almost crisis like during the summer (March-June) when the deficit is nearly 695,550 gallons, as per the respective Municipality. Additionally, the regional projections for climate change shows increased temperature and decreased precipitation coupled with short duration heavy rainfall events which are likely to lead to increased water scarcity and health impacts. The stakeholders which include academia, NGOs, community representatives, other para government department, in both cities comprehended that restoration and rehabilitation of the traditional water harvesting system and also the refurbishment of the existing catchment area will not cost a huge amount of money, but yet can leave a positive impact on a great extent of the city's water resources. Hence, both the cities, through the SLD process, recognized the significance of and need to conserve their traditional water harvesting systems - Baoli (Natural Spring); along with need to restore the existing water infrastructure to make the city more resilient to climate change.

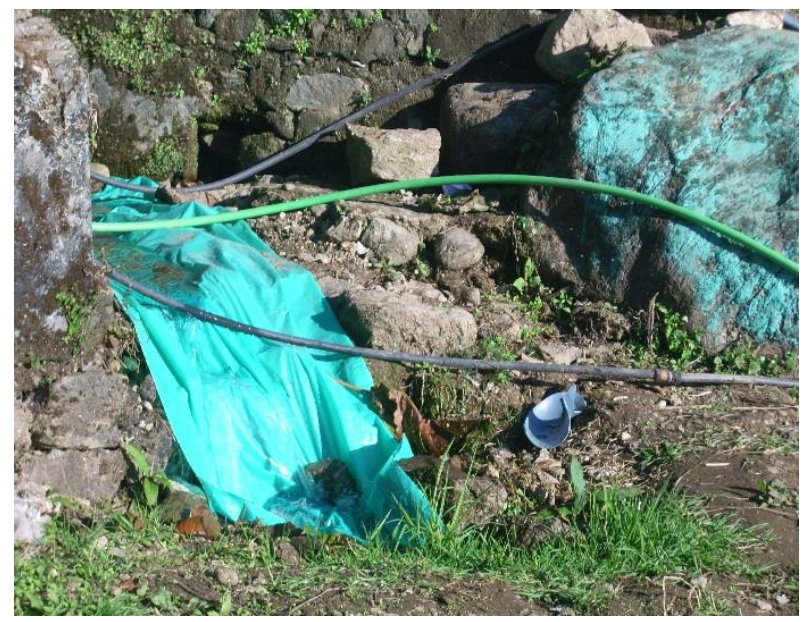

Figure 1: One of the degraded catchment Source: Author

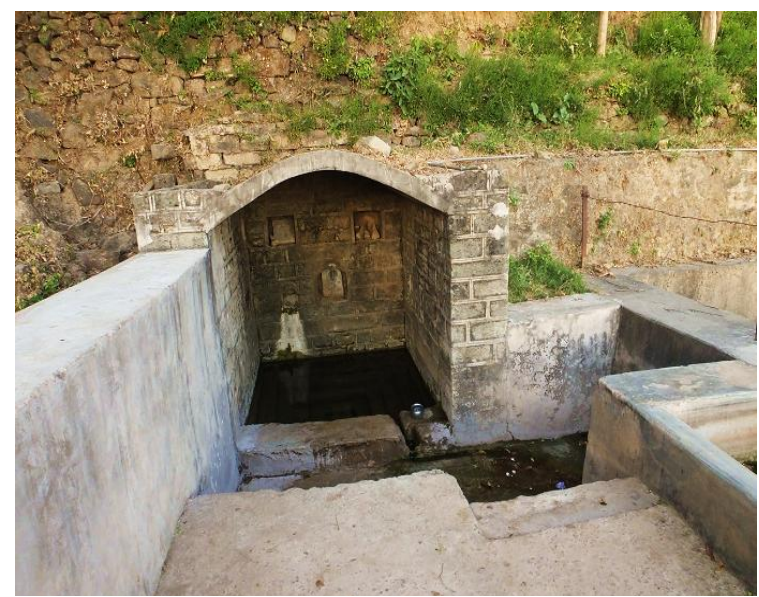

Figure 2: Traditional water harvesting system in Shimla - Baoli (Natural Spring) Source: Google image

Whereas, Gangtok recognized the essential need to adopt a proper Solid Waste Management system. Inefficient collection, lack of segregation, estimated around 50-60\% recycling of waste, resulting in the 
rapid filling up of dumping sites and also open dumping in the public places; especially in the open drains and Jhoras (natural streams). This is due to solid waste being dumped in open drains and Jhoras and clogging them, thus diverting water and causing landslides that result in infrastructural, financial and human loss. The projected short duration heavy rainfall can lead to more incidences of landslides if there is no free flow of water through the Jhoras and therefore, there is a need to tackle the dumping of the solid waste into the Jhoras, especially near the market or commercial areas.

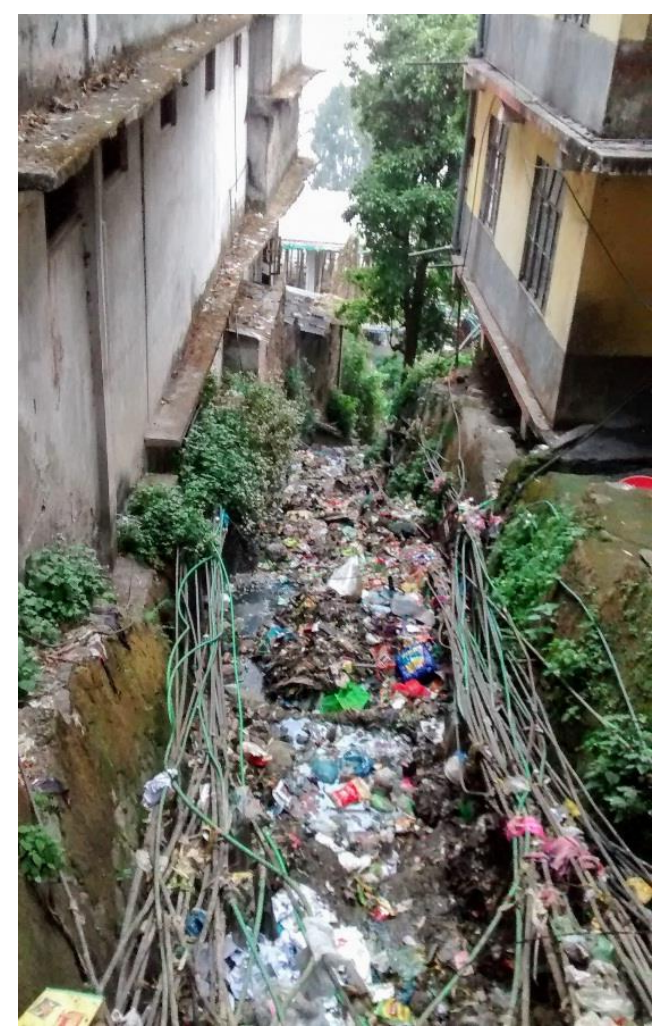

Figure 3: One of the Jhoras (natural streams) that is clogged by Solid Waste, in Gangtok Source: Author

To translate these city level climate strategies and projects into reality, the cities need funding. Financing has been proved to be the stumbling block towards implementation of the resilient infrastructure. For instance, the operating expenditure and revenue relation of Shimla were analyzed (shown in the below diagram) under the 'Climate Change Adaptation Project Preparation and Financing in Urban India, a Project Report' which was prepared for the USAID Adapt Asia-Pacific project. The data was analyzed for the period 2009-2012 and made a future projection for 2013- 2017 using the City Infrastructure Investment Priority Programming (CIIPP) toolkit which has been developed by the Cities Development Initiatives in Asia (CDIA). 


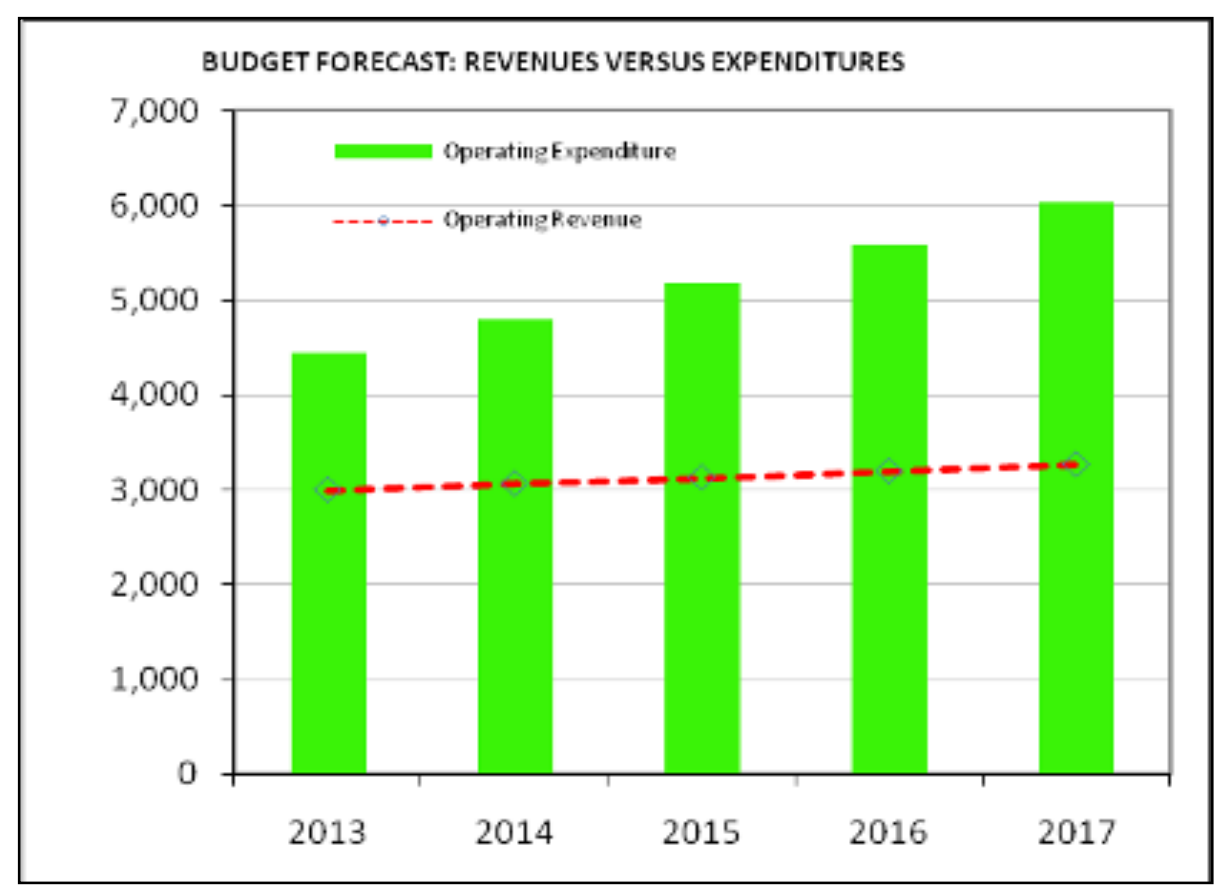

Figure 4: Budget forecast of Shimla, revenue versus expenditure

The graph depicts the fragility of the Shimla Municipal Corporation's financial system. The expenditure is projected to be double the expected revenue. Hence, the city is and would continue to be very dependent on grants from the state government and other sources, and would not be in a position to take a loan as its debt service capacity is negative.

However, in addition to a poor revenue base, these three cities are also constrained by inefficient organizational and human resources, lack of conducive environment for climate based actions, red tapism, bureaucratic diplomacy and limited jurisdictional empowerment. The Urban Local Bodies (ULBs) of the aforesaid three cities do not have the capacity to meet the criterion or to follow the procedures to tap into the international climate financing options. They receive only tied funds from the state and federal government for developmental activities. Apart from this, there is a lack of awareness on climate change and a lack of recognition for the need for adaptation projects. Low political will towards climate change impacts is also a deterrent.

"Kurseong city is located at a height of 1800 meters on a sloppy hill; highly vulnerable to the impacts of climate change. Unfortunately, there is a huge scarcity of skilled human resources in our municipality, we only 4 technical staff serving to 50,000 inhabitants of the city and also dealing with various issues that we face very often. Most importantly, we are a poor municipality in terms of financial resources. However, it does not mean that we can afford to stop acting to combat the impacts of climate change our city is experiencing. We have to look at every possible avenue. We have to start with small actions which will contribute to bigger change making process. We are enriched with the local knowledge that we have to utilize. The ultimate goal is to make Kurseong a resilient, healthy and livable city"- Mr. Sanjay Prasad, Urban Planner, Kurseong Municipality, India.

Therefore, through this process, the climate core team of the respective cities understood the need to integrate the identified projects with the existing programmes of government. Apart from that, spring 
rejuvenation, catchment area restoration or managing waste at the source to avoid clogging of the drains are not priority projects for these cities as the return of investment on these projects is low. So, obtaining a resolution from the council and the approval from the finance department to invest in linking with the ongoing federal government schemes is a troublesome process.

Hence, an innovative financing approach steered by the city municipalities was adopted to encourage and motivate cities to access climate based funds on their own. This is crucial to ensure ownership of the adaptation measures at the city level. Therefore, a climate core team in each city steered the initiative and recognized the effectiveness of undertaking a pilot demonstration project to showcase some tangible actions and changes on the ground. Hence, along with other cities, the climate core team in cooperation with their respective city authorities participated in the competition of accessing the ICLEI-ACCCRN Engagement Building Small Grants Fund which is supported by the Rockefeller Foundation and is managed by ICLEI South Asia to undertake some pilot implementations. Shimla submitted a proposal on rejuvenating the traditional water sources (Baoli/ natural spring) for 14 out of 34 such sources to augment water security in the Shimla Municipal Corporation area. Whereas, Kurseong city chose to revitalize the existing water catchment areas for 5 out of 9 catchment areas to improve the water quality and quantity downstream. Gangtok identified the necessity of setting up a proper collection, segregation mechanism and solid waste processing unit, installing a bio composting plant for composting vegetable waste at a vegetable market and at shopping areas of the city. The proposals were evaluated through various indicators such as rational and outcomes, impact and beneficiaries, work plan and budget, sustainability of the projects etc, and the proposals for all the three cities along with three more were approved. The implementations are nearly over in all three cities.

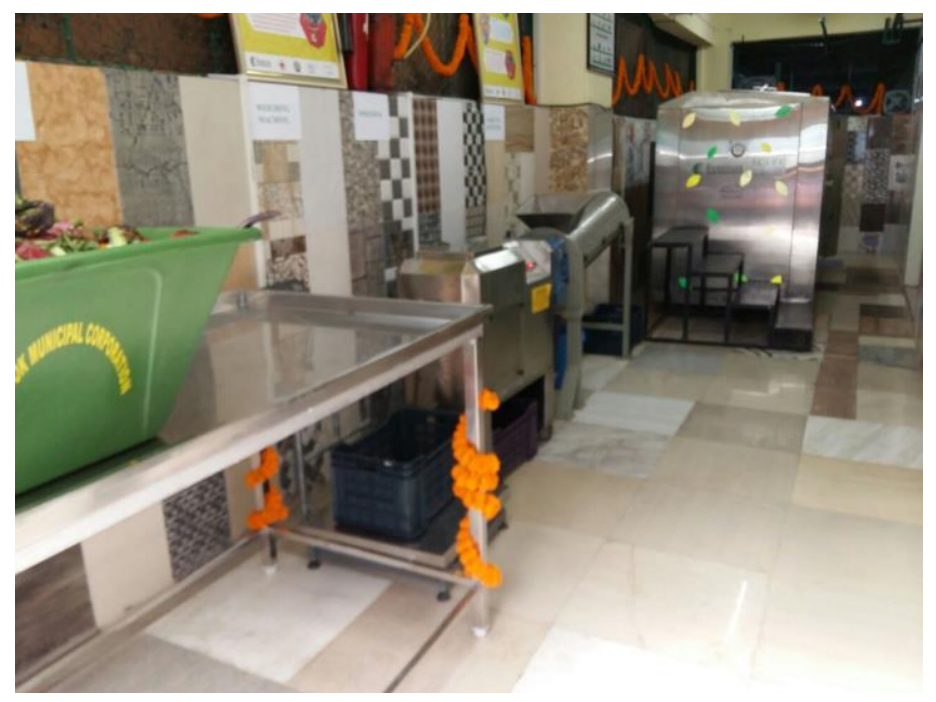

Figure 5: inauguration of the Organic Waste Converter (OWC) plant in Gangtok Source: Gangtok Municipal Corporation

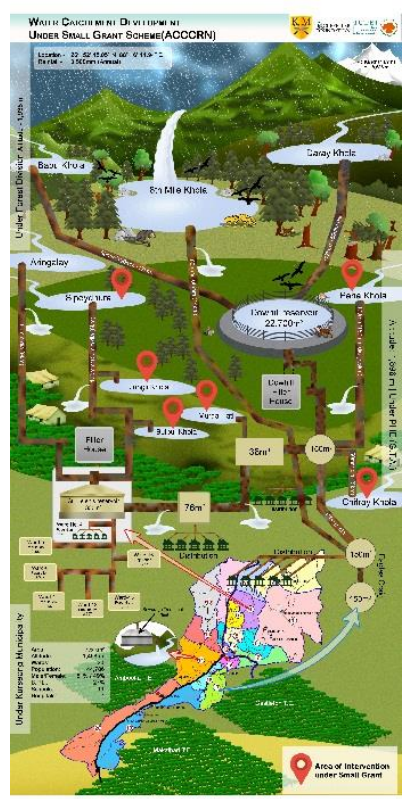

Figure 6: Assessment of water supply system of Kurseong city

Source: Kurseong Municipality

"Gangtok Municipal Corporation is relatively a new institution, only formed in 2010. We have not got the full autonomy, we share accountability with the state urban development department as well. It is 
not always very easy to mobilize funds from the state government exclusively for climate resilient projects. Therefore, we have to adopt the pragmatic ways. We can't be dependent on the international funding sources, we have to always think: what is the sustainability of the particular project beyond the project period? So, we have to see a long term solution. One of the straightforward ways is to integrate the resilience aspect with the ongoing flagship programs of the federal government. Additionally, the local citizens need to be involved in the resilience building process. Residents of Gangtok must have the same understanding about what problems are faced by the city, otherwise any urban resilience practices will not work." - Mr. Shakti Singh Choudhury, Hon'ble Mayor, Gangtok Municipal Corporation.

Contingent on the positive results of the pilot projects and response from the stakeholders which include beneficiaries and other supporting actors, the respective local government of Shimla, Kurseong and Gangtok passed the resolutions without having any facilitation by the climate core team and have already integrated the projects with the existing schemes of the Government of India to facilitate convergence of funding for implementation and upscaling. Shimla Municipal Corporation has already included the rejuvenation of the rest of the springs (20 in total) in the Service Level Improvement Plan (SLIP) of Atal Mission for Rejuvenation and Urban Transformation (AMRUT), a scheme by the Ministry of Housing and Urban Affairs (MoHUA), Government of India (GoI); consisting of capacity building, reform implementation, water supply, sewerage and septage management, storm water drainage, urban transport and development of green spaces and parks. Kurseong has taken up a resolution to execute the same model in the other catchment areas using the fund of 14th Finance Commission, Govt. of India. Gangtok has already integrated the project with the Swach Bharat Mission (SBM) programme; a flagship programme by MoHUA and the Government of India (GoI) to improve the sanitation system of Indian Cities. Further, local level institution has also been formed for Operation and Maintenance (O\&M) of the projects by the respective municipalities. For intense, ward committee which consists of mainly beneficiaries, local councilor etc. (elected representative of the ward) in Kurseong has been formed for the O\&M of the rejuvenated water catchment areas and also the same committee will look after the Solid Waste Management issues of the respective ward.

In terms of resilience building actions, most of the cities go for centralized infrastructure projects for which a large amount of financial support is required. The South Asian cities are mostly unable to tap into the funding available for resilience building activities. The aforesaid three cities took a different path by identifying local level issues and then undertaking a pilot through the abovementioned Small Grant Fund to create a model which can be integrated with the existing schemes. Thus, the success story of the aforesaid projects and the process has been followed to build the capability of these three cities to combat impacts of Climate Change, can act as a model for other Himalayan and mountain cities with fragile ecosystem.

"The authors declare no conflict of interest"

(C) 2018 by the authors; licensee MDPI and IFoU, This article is an open access article distributed under the terms and conditions of the Creative Commons Attribution license. 